its omissions. Similarly the presentation of original studies composing the bulk of the book is uneven and often seriously lacking in detail. They might more suitably have been submitted in conventional format to standard. journals. Finally, the attempt at educing a grand theoretical design based on the concept of integration is interesting but does not offer any very useful guidelines to the researcher in the area of development.

These, however, are general criticisms. The book contains many good specific insights and brings together some diverse and little-known material. The latter feature reflects the broad background of experience of the author and his professional associations with such figures as J. P. Scott, Williamina Himwich, J. Myslivecek, R. L. Sidman and J. L. Fuller. Nor can one underestimate the amount of effort put into some of the studies and the value of some of the basic data presented. Developmental psychologists should find the book a useful addition to their libraries.

\section{W. R. THOMPSON}

\section{Undergraduate Mineralogy}

Mineralogy for Students. By M. H. Battey. Pp. xii + 323. (Oliver and Boyd: Edinburgh, January 1972.) £4.

THIS book aims to provide a unified treatment of the principles of mineralogy combined with descriptions of the commoner minerals in a form that is suitable for first degree courses in geology or mining.

In the first of its two parts, "Principles and Methods," crystal chemistry, geometrical crystallography, the physical properties of crystals (with an understandable emphasis on optics), $X$-ray crystallography and mineral associations are among the topics discussed. Inevitably, exploration of such a wide range of subjects in only just over half the text means that the treatments must in places be rather superficial; nevertheless, the presentation is coherent and informative, and is supplemented by suggestions for further reading which one hopes the student will pursue. In the second part, "Descriptions of Minerals", the structural features, crystallographic constants, habit, optics, occurrences and so forth of the commoner rock-forming minerals are set out systematically. Such data are basic to books of this kind, but in this volume are clearly and succinctly presented in a manner that the student will generally appreciate; in particular the structural diagrams are to be commended for the effort to remove confusing detail. The four brief appendices include elementary determinative tables; one might hope that the historical nomenclature of crystal classes also mentioned here could now be decently buried. Within its brief, the book generally achieves its objectives and stands comparison with the best of overseas texts which have mainly occupied this ground so far. But, even in a first degree course, mineralogical studies cannot be divorced from their context, and it is disappointing to find that the physico-chemical principles essential to a fuller understanding of rock-forming processes are deliberately omitted.

P. GAY

\section{Nicotinic Acid}

Metabolic Effects of Nicotinic Acid and its Derivatives. Edited by K. F. Gey and L. A. Carlson. Pp. 1251. (Hans Huber: Bern, Stuttgart and Vienna, 1971.) 345 francs; 310 DM.

THIs book contains the proceedings of a workshop held in Films, Switzerland, in March 1970. The importance of nicotinate (and its derivatives) in pharmacology and therapeutics, and hence the basis for this workshop and these extensive proccedings, lies in its effects in lowering plasma cholesterol and triglyceride concentrations and its potential value in the treatment of atherosclerosis. The book contains some one hundred and twenty papers in all by a number of distinguished scientists in fields of metabolism, metabolic regulation and pharmacology. The editors are well known to all in these fields and they are to be congratulated on the timeliness of the topic, on the coverage given, on the quality of the published proceedings, and on its undoubted worth and value. This book reviews pharmacokinetics of nicotinate and derivatives, metabolism of nicotinamide nucleotides, mobilization and metabolism of fatty acids, including the role of cyclic AMP, the metabolism of triglycerides and the role of lipoprotein lipase, cholesterol metabolism, certain aspects of carbohydrate and protein metabolism and hormonal effects and actions. The unifying theme is aptly described in the title of the book.

It is perhaps inevitable with so many participants that the subject is somewhat fragmented, that some presentations are incomplete, and a number of the papers are extremely short. Nevertheless it is a comprehensive coverage of the physiological role of nicotinate and its pharmacological effects. Quite apart from the bibliography associated with each of the individual papers there are seventy pages of general bibliography in the supplement. The printed discussion of the papers is well directed and contains some important statements and questions.

This book should form a valuable work of reference for those interested in pharmacology, in cardiovascular disease, in lipid metabolism and in metabolic regulation. The quality of reproduction and editing is quite outstanding. As a specialist work in this field it can be thoroughly recommended.

\section{P. J. RANDLE}

\section{Educating Physicists}

Teaching Physics-An Insoluble Task? Edited by Sanborn C. Brown, F. J Kedves and E. J. Wenham. (Proceedings of an International Conference on the Education of Teachers of Physics in Secondary Schools, Hungary, September 1971). Pp. xiv +261. (The MIT Press: Cambridge, Massachusetts, and London, 1971.) \$10.

IT isn't only the football manager who has trouble in bringing together the separate skills of distinguished players. Editors of congress proceedings find similar problems and this record of the IUPAP meeting held in Eger in the summer of 1970 is no exception. Certainly the participants included many illustrious names in the field of science education and were led by Kapitza whose opening address was full of his usual wisdom. Nevertheless the invited papers on a wide range of topics from constraints on teacher education to the technology of physics education did not fit smoothly together and give one the understandable impression of individual prima donnas playing together for the first time. The editors attempted, as they say, to bring across through the very highly edited proceedings something of the flavour of the group discussions to those who missed the opportunity of attending the meeting.

Unfortunately, verbatim reports frequently bring in unnecessary redundancies and divergencies and I doubt whether the hoped-for tang comes across well to those of us who missed the international. One must hope that the benefits will be apparent to those who were there although I found it particularly difficult to believe that the discussions which led, for example, to the rather well worn recommendations of the working group for curriculum innovation could have been too novel or exciting. Throughout the text there are some useful biographical lists.

It is easy to be critical of proceedings of this kind, and I am sure that the editors realized that their own task of presenting them was far more difficult than the teaching of physics.

K. W. KEOHANE 